\title{
Knowledge, help-seeking and efficacy to find respite services: an exploratory study in help-seeking carers of people with dementia in the context of aged care reforms
}

\author{
L. Phillipson ${ }^{1,2^{*}}$ (D, K. Johnson ${ }^{2}$, E. Cridland ${ }^{2}$, D. Hall ${ }^{2}$, C. Neville ${ }^{3}$, E. Fielding ${ }^{4}$ and H. Hasan ${ }^{2}$
}

\begin{abstract}
Background: Research highlights the need for carers of people with dementia to acquire relevant and timely information to assist them to access appropriate respite services. Unfortunately, negative experiences of information-seeking can create additional stress for carers and contribute to delays in up-take, or not using respite services at all.

Methods: Cross-sectional survey data was collected from a convenience sample of $n=84$ carers of older people with dementia living in the Illawarra-Shoalhaven region of NSW, Australia. We assessed knowledge, attitudes, information seeking behaviours, and unmet need for respite services in 2016, following national aged care reforms.

Results: Over the previous 12 months, $86 \%$ of carers sought respite service information. The majority (73\%) of all carers reported an unmet need for respite services, and were relying on personal networks to provide support for respite information. Few utilised the new government gateway 'My Aged Care' phone line (11\%) or website (25\%). However, $35 \%$ used a pre-existing helpline to access short term or emergency respite. We found a preference for interpersonal information sources, including local doctor (65\%), professionally and volunteer led carer support groups (49\%), and family and friends (46\%). Those using four or more information sources showed higher capacity to name local respite services. Respite service information seekers were more likely to be caring for someone with behavioural problems, to have received assistance to access services, and to have used respite services in the past 3 to 6 months.

Conclusions: New reforms in the Australian aged care sector have not adequately responded to the needs of carers of people with dementia for respite service information and support. Wider, community-based messaging promoting positive service options and the provision of active personal support is required to address the unmet need for respite in carers of people with dementia.
\end{abstract}

Keywords: Carers, Dementia, Respite, Information seeking, Service use, System reform

* Correspondence: Iphillip@uow.edu.au

${ }^{1}$ School of Health and Society, Faculty of Social Sciences, University of Wollongong, Wollongong, Australia

${ }^{2}$ Australian Health Services Research Institute, University of Wollongong,

Wollongong, Australia

Full list of author information is available at the end of the article

(c) The Author(s). 2019 Open Access This article is distributed under the terms of the Creative Commons Attribution 4.0 International License (http://creativecommons.org/licenses/by/4.0/) which permits unrestricted use, distribution, and reproduction in any medium, provided you give appropriate credit to the original author(s) and the source, provide a link to the Creative Commons license, and indicate if changes were made. The Creative Commons Public Domain Dedication waiver (http://creativecommons.org/publicdomain/zero/1.0/) applies to the data made available in this article, unless otherwise stated. 


\section{Background}

In 2015, an estimated 47 million people were living with dementia throughout the world, with this number expected to triple by 2050 [1]. In Australia, dementia affects almost 1 in 10 people aged 65 and over, with estimates of 354,000 in 2016, and its prevalence increasing by $40 \%$ from 2006 to 2016 [2]. Dementia is a degenerative neurological syndrome which impacts on multiple areas of function including memory, communication, and ability to perform activities of daily living [3]. While some people with dementia require institutional care, the vast majority live at home $[3,4]$. Having a co-resident carer increases the likelihood that people with dementia will live at home longer [5]. Formal services in the community can assist people with dementia and their carers via: help with home duties; support through counselling services and support groups; and the provision of 'respite' services or substitute care [6]. Respite as an outcome can be achieved through the use of multiple strategies. In this paper, we are focused on engagement with formal respite services which typically include planned and emergency services in-home, centre-based, out-of-home or short stays in residential care services [7].
In the Australian context, access to all service types is possible. However under new reforms, this occurs via a number of different pathways and programs (see Fig. 1). Respite service use provides carers with a break to attend to their own health or social needs, and can also enable people with dementia to participate in meaningful and appropriate activities or opportunities for social engagement and stimulation [8,9]. Consumer directed care systems (where the focus for funding of supports is tied to meeting the specific goals of the person with the disability) enforce this emphasis with carer benefit only positioned as a 'secondary' or indirect outcome of service use by the person with the disability [10].

Despite respite being consistently identified by carers of people with dementia as one of their critical unmet care needs [11], the overall proportion who use respite and other support services is low $[12,13]$. Research has highlighted a number of factors leading to low uptake of respite services including beliefs regarding poor service quality, guilt or the possibility of negative outcomes, a confusing and fragmented dementia services care environment, lack of availability and flexibility in service provision, and poor communication and referrals to support services $[13,14]$.

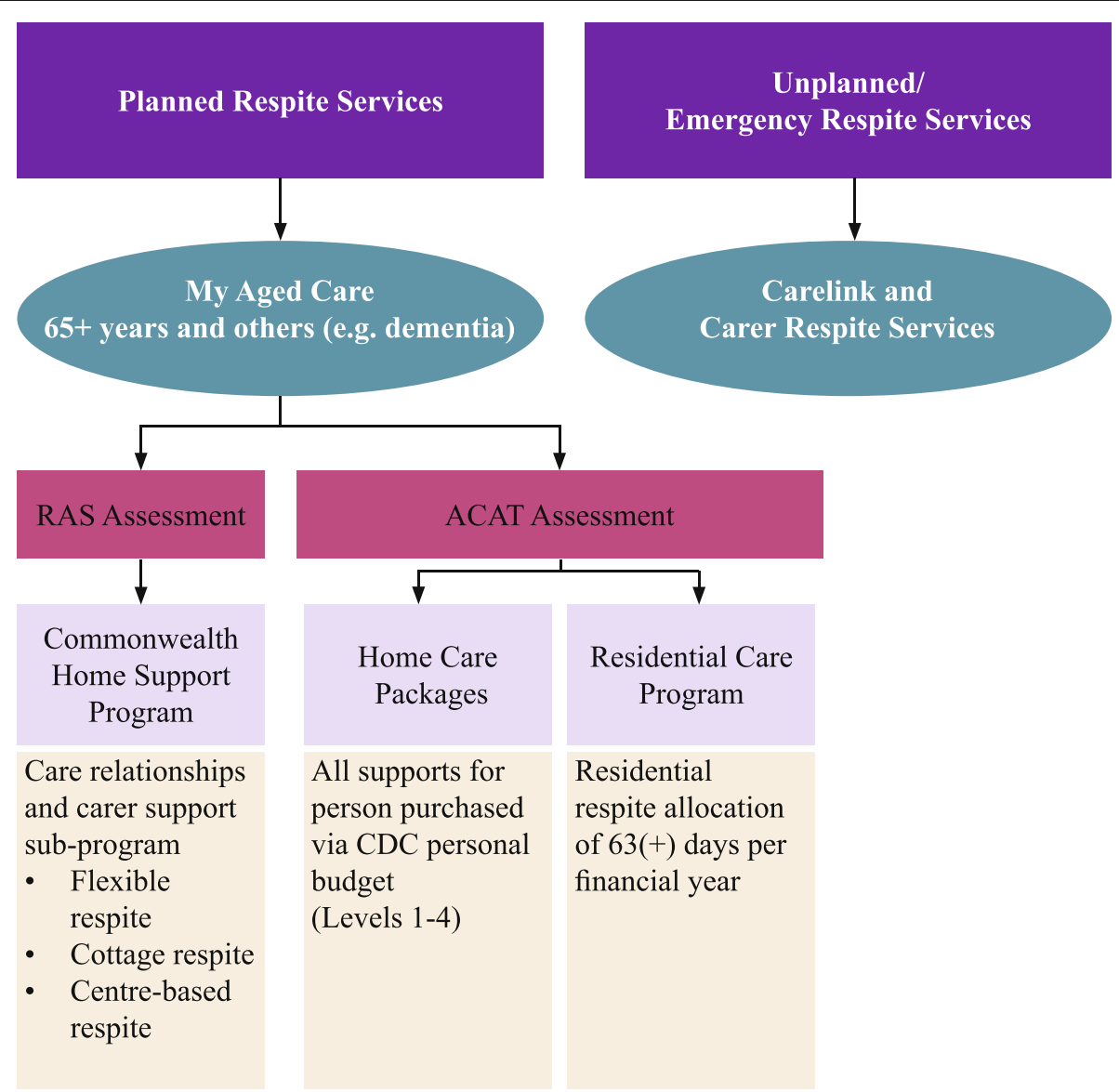

Fig. 1 Respite in the Australian aged care system 


\section{Knowledge of respite services and efficacy to access}

Carers of people with dementia are often responsible for proxy help-seeking and care related decision making on behalf of the person with dementia [15] as well as for personal help-seeking to find support for their own needs [14]. With regards to respite seeking, previous research highlights the critical need for carers to access appropriate information about the right services, at the right time [13, 16-19]. Knowledge of the service system has been associated with generic respite service use and non-use [18, 20], and non-use of centre-based respite [13].

Sourcing information about respite can add to the stresses associated with caring for someone with dementia. Robinson et al. [16] describe the mental stress and emotional turmoil for carers of people with dementia searching for service information in a complex system. Such negative experiences of information-seeking can lead to carers either delaying up-take, or not using respite at all [11, 16, 21].

Lack of awareness or confusion about the range of services available can inhibit early take-up of services, and, in turn, contributes to a sense that respite services should only be used as a last resort [12, 22]. The fact that 'respite' has also often been accessed through numerous funding programs, with differing eligibility and fee requirements, can be confusing for the carer and the person with dementia. This confusion can preclude early use and hinder information about available services or support in care planning, including how respite could be accessed in an emergency $[12,22]$.

In Australia, as part of the broader 'Living Longer Living Better aged care reforms [23], a single gateway service for older people called 'My Aged Care' was introduced in July 2013 [24]. This program includes a telephone helpline and website to assist with information and referral but does not include the option for access to a single 'named' contact which has been identified as important for people living with complex needs such as those with dementia [17].

Australian reforms also supported changes to the administration of planned respite services, with an amalgamation of funding for planned respite services from the previous National Respite for Carers Program into the new Commonwealth Home Support Program [9, 25]. Subsequently, in December 2015, a program of reform for carer supports commenced, including the introduction of a single Carer Gateway (website and telephone line) to promote carer access to information, education, and counselling services [26]. At this stage, access to short term and emergency respite remains with the Commonwealth Carer Respite Centres (CCRCs) who previously provided carer information, education, counselling and arrangements for emergency respite services as well as referral for planned respite [27]. Unfortunately, for carers of people with dementia, the reforms now require them to negotiate with three different programs: My Aged Care for planned respite services [25], CCRCs for short term and emergency respite [27]; and the Carer Gateway for information, education and counselling [26]. While the reforms in Australia aim to improve services for carers and people with dementia, they may lead to increased confusion as people attempt to navigate a system in transition [9]. Currently, the impact of these reforms on provision of information and support to access respite for carers of people with dementia is unknown.

\section{Research objectives}

This study aimed to explore the knowledge, information seeking behaviours, and perceived need for respite of carers of people with dementia following aged care reforms in Australia. Of particular interest was carers' knowledge of local respite services; where carers sought information about local respite services; their rating of the usefulness of these sources; and, who (if anyone) helped them find information. The study also has international significance given the increased transition to consumer directed care systems in the UK, US, and parts of Europe [28].

\section{Method}

\section{Survey}

The survey tool utilised a number of standardised scales. Variables assessed included demographic characteristics (e.g. gender, age, education, languages others than English; caregiver relationship, financial status) as well as knowledge of respite services [29]. We also assessed carers' perceptions of the level of the person's cognitive disability [30]. Factors which impact on service use were assessed (e.g. receiving caregiver training). Finally, carers' need for respite was assessed using both perceived and evaluated need standardised scales including: Role Captivity [30], Zarit Burden scale [31] and Family Caregiver Self-efficacy for Managing Dementia [32], as well as current and intended use of respite services, and where respondents looked for information. Problematic Behaviour for the person with dementia [30] was also used as an indirect measure of carer need for respite.

\section{Sample}

There is no accurate sample frame for carers of people with dementia in the community in Australia. As such, convenience sampling of help-seeking carers was conducted using community and service provider channels in the study region. These included: the CRCC, Aged Care Assessment Teams (ACAT), respite service providers, and carer support groups. Data collection was conducted from September 2015 to July 2016. A total of 494 paper surveys were distributed. Overall, eighty-four of a possible 461 surveys were returned, resulting in an estimated response 
rate of $18.2 \%$ (the rate may be higher due to distribution to the same carer by multiple services, or non-compliance with survey distribution by services). Thirty-three returned surveys were excluded as ineligible. Seven duplicates were identified in the returned sample and were excluded. See Fig. 2.

\section{Analysis}

Simple descriptive analysis was utilised to describe the characteristics of those seeking information for respite. As some respondents had random missing data, data imputation was conducted in cases where less than $20 \%$ of data was missing within responses for a particular scale, specifically on the scales of Cognitive Status (8 participants) [30], Problematic Behaviour (13 participants) [30], and Family Caregiver Self-efficacy for Managing Dementia (2 participants) [32]. The mean score for a given respondent on a specific scale was manually imputed. Relationships between categorical variables were analysed through Chi-square test for independence or Fishers exact test (for tests with a 2 by 2 table or where the minimum expected cell frequency assumption was violated). To examine relationships between groups on continuous variables, $t$-tests were used for those variables with normal distributions and Mann-Whitney $U$ tests for those with non-parametric data. Significance was set at $p=.05$ with Bonferroni adjustment for multiple comparisons.

\section{Results}

\section{Demographic characteristics}

The demographic characteristics of carers and of the person with dementia are provided in Table 1 . The sample represented both male and female carers and people with dementia, as well as different types of carer relationships (e.g., spousal and non-spousal caregivers). The majority of care givers were female and lived in the same house as their family member or friend (person with dementia). Most of the people with dementia reported a medical diagnosis of dementia, with the majority having a primary diagnosis of Alzheimer's disease. Many respondents reported an unmet need for respite. Many carers were receiving support from formal services and/or from family and friends, however $18 \%$ received no support from either source. Despite most receiving some form of support, many carers reported an unmet need for respite services. See Table 1.

\section{Respite information seeking behaviours of carers}

The majority of respondents $(n=71,86 \%)$ reported actively seeking respite information during the past 12 months. Of those who had looked for information about local respite services, the majority or many sought information from their general practitioner (GP) or local doctor, with slightly less than half using either volunteer or support carer groups or family or friends. Just over a third had utilised a government-funded helpline (CRCCs) which is the access point for emergency respite. Only 16\% had utilised the My Aged Care helpline, however most rated it as an excellent or good information source. Other sources (27\%) were reported as specific service providers, local councils, specialist doctors and ACAT. It should be noted that the three highest used sources of information were person to person sources, with the fourth highest a helpline rather than internet source. Only one quarter had utilised the My

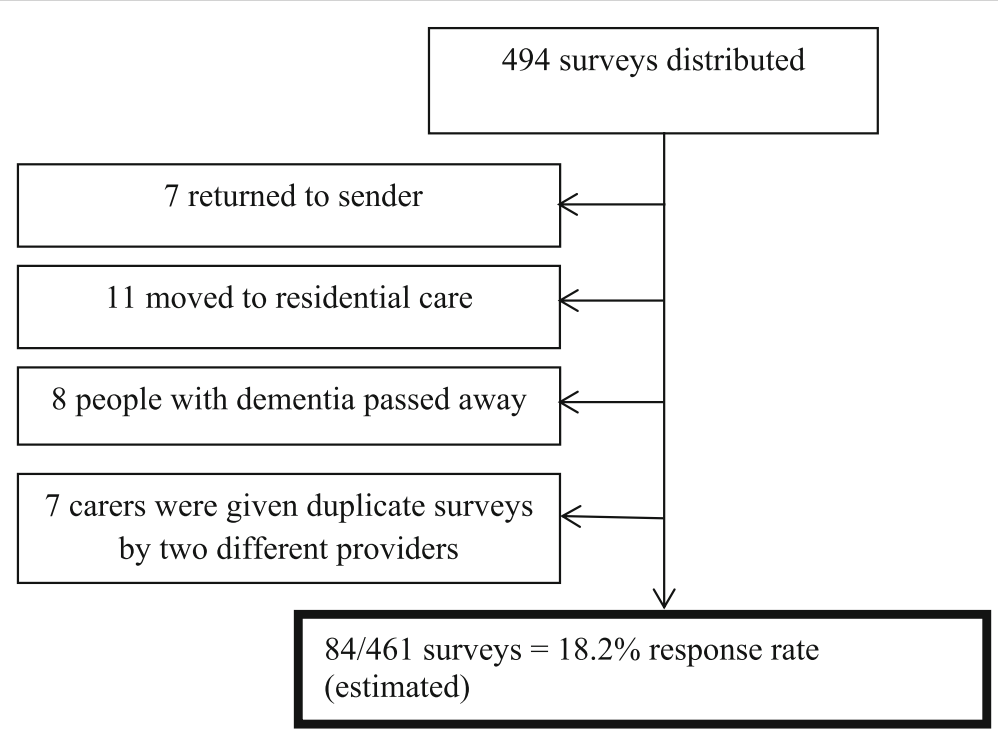

Fig. 2 Survey responses 
Table 1 Characteristics of study participants

\begin{tabular}{|c|c|}
\hline Demographic variable & Total $n=84$ \\
\hline \multicolumn{2}{|l|}{ Carer } \\
\hline Age $^{a}$, Mean (range) & $70(38-92)$ \\
\hline Gender ${ }^{a}$. Female $n(\%)$ & $62(74 \%)$ \\
\hline Language spoken at home ${ }^{a}$, English $n(\%)$ & $72(86 \%)$ \\
\hline Relationship, spousal $n(\%)$ & $59(70 \%)$ \\
\hline \multicolumn{2}{|l|}{ Person with dementia } \\
\hline $\mathrm{Age}^{\mathrm{a}}$, Mean (range) & $79(61-94)$ \\
\hline Gender ${ }^{a}$. Female $n(\%)$ & $32(39 \%)$ \\
\hline Language spoken at home, English $n(\%)$ & $68(83 \%)$ \\
\hline Medical diagnosis, yes ( $n(\%)$ & $74(90 \%)$ \\
\hline \multicolumn{2}{|l|}{ Type of dementia, $n(\%)$} \\
\hline Alzheimer's & $42(56 \%)$ \\
\hline Vascular & $12(16 \%)$ \\
\hline Lewy Body & $3(4 \%)$ \\
\hline Other & $9(12 \%)$ \\
\hline Unknown & $9(12 \%)$ \\
\hline Pearlin Cognitive Status ${ }^{\mathrm{b}},{ }^{\mathrm{a}}$ Mean, SD & $2.42(0.64)$ \\
\hline \multicolumn{2}{|l|}{ Respite knowledge and behaviours } \\
\hline Tried to find respite information, yes $n(\%)$ & $71(85 \%)$ \\
\hline $\begin{array}{l}\text { Knowledge, Ability to name three respite } \\
\text { services }^{\mathrm{a}} \text {, yes } n(\%)\end{array}$ & $42(51 \%)$ \\
\hline Receive some support (formal or informal), yes & $67(82 \%)$ \\
\hline $\begin{array}{l}\text { Mean (SD), number of respite services used in } \\
\text { past 3-6 months }\end{array}$ & $1.32(0.93)$ \\
\hline Would like more respite ${ }^{a}$, yes & $51(68 \%)$ \\
\hline
\end{tabular}

Note. ${ }^{a}$ Valid percent is reported due to missing data. ${ }^{\mathrm{b}} 8$ items, range 0 (Not at all difficult) to 5 (Can't do at all)(higher score denoting poorer perceived function)

Aged Care website (the new portal for accessing aged care services including planned respite) with $72 \%$ rating it as an excellent or good source of respite information. Apart from My Aged Care, other internet sites were rarely utilised as information sources about respite. The majority of respondents rated information sources as good or excellent, with the exception of a Carers NSW helpline and website, and a CRCC website which has now been discontinued. See Table 2 .

A number of carers reported looking for information from more than one source: 33 (47\%) used two-three sources and 27 (38\%) four or more sources. The remaining carers, 11 (16\%) used only one source. Those using four or more sources were more likely to be able to name three respite services [ $78 \%$ ( 4 or more sources) vs. $46 \%$ (one source) or $42 \%$ ( 2 to 3 sources), $\chi^{2}=8.172$ (2), $p=.017$ ].

\section{Relationship between types of support and respite knowledge}

Respondents were asked to name three respite services or facilities within their local area. Forty-two (52\%)
Table 2 Carers' scoring of sources of respite information

\begin{tabular}{lllll}
\hline Source $(n=68)$ & Type & $\begin{array}{l}\text { Excellent/ } \\
\text { Good }\end{array}$ & $\begin{array}{l}\text { Fair/ } \\
\text { Poor }\end{array}$ & Total \\
\hline Your GP or local doctor & Person & 34 & 12 & $46(65 \%)$ \\
Carer support group & Person & 33 & 2 & $35(49 \%)$ \\
Family or friends & Person & 26 & 7 & $33(46 \%)$ \\
Commonwealth Respite & Helpline & 23 & 2 & $25(35 \%)$ \\
and Carelink & Website & 13 & 5 & $18(25 \%)$ \\
My Aged Care & Person & 16 & 3 & $19(27 \%)$ \\
Other ₹ & Helpline & 7 & 1 & $11(16 \%)$ \\
My Aged Care & Person & 7 & 1 & $11(16 \%)$ \\
$\begin{array}{l}\text { Dementia Advisory Service } \\
\text { Alzheimer's Australia National }\end{array}$ & Helpline & 5 & & $9(13 \%)$ \\
$\begin{array}{l}\text { Dementia Helpline } \\
\text { Carers NSW }\end{array}$ & Helpline & & 3 & $5(7 \%)$ \\
$\begin{array}{l}\text { Dementia Illawarra Shoalhaven } \\
\text { Carers NSW }\end{array}$ & Website & 2 & & $4(6 \%)$ \\
Commonwealth Respite and & Website & 1 & 2 & $4(6 \%)$ \\
Carelink & Website & 1 & 1 & $3(4 \%)$ \\
HSNet & Website & & & $0(0 \%)$ \\
\hline Note. & & &
\end{tabular}

Note. ‡ 'Other' included specific service providers, local councils, specialist doctors and Aged care services

respondents named three respite services, 31 (38\%) could name one to two services, and $10(8 \%)$ could not name any respite services within their local area. It was hypothesised that those who were currently receiving support from formal or informal sources, would have a higher knowledge of respite services. Knowledge of local respite services was not related to having received carer training or being a member of a support group. Those who reported they had assistance to access services were significantly more likely to be able to name three respite services $(p=.007$, Fisher's Exact Test). See Table 3. Of those $n=53$ who had assistance, $85 \%$ reported formal sources (doctors, social workers, respite services), 9\% reported informal sources (family or friends), and 6\% reported both formal and informal sources.

\section{Relationship between ever seeking information and perceived or evaluated need}

With regards to perceived or evaluated 'need, informationseekers reported significantly higher scores for their family member or friend's problem behaviours $(U=161.00$, $\mathrm{Z}=-2.98, p=.003)$. See Table 4 .

\section{Discussion}

The vast majority of carers reported they had tried to find information about local respite services in the past 12 months. Whilst most had some knowledge of local respite services, almost $10 \%$ could not name any respite services within their local area. Very few had utilised the new service gateway website or telephone helpline. Of 
Table 3 Relationship between types of support and knowledge of respite services

\begin{tabular}{lllll}
\hline Carer Characteristics & Total, $n=81$ & Named 3 services $n=42$ & Named $<3$ services $n=39$ & $P^{*}$ \\
\hline Formal support, yes $^{\mathrm{a}}$ & $50(64.9 \%)$ & $30(75.0 \%)$ & $20(54.1 \%)$ & $13(37.1 \%)$ \\
Informal support, yes $^{\mathrm{a}}$ & $40(52.6 \%)$ & $27(65.9 \%)$ & $22(56.4 \%)$ & .061 \\
Caregiver training, yes $_{\text {Carer Support Group, yes }}^{\mathrm{a}}$ & $43(53.1 \%)$ & $21(50.0 \%)$ & $20(47.6 \%)$ & .021 \\
Assist to find services (navigate), yes $^{\mathrm{a}}$ & $40(50.0 \%)$ & $20(52.6 \%)$ & $20(62.5 \%)$ & .823 \\
\hline
\end{tabular}

Note. Cell values represent frequencies (\%) for categorical variables. All analysed using Fisher's exact test. *Significance set at $p \leq 0.01$ due to Bonferroni correction. ${ }^{a}$ Valid percent is reported due to missing data

those that had, a higher proportion rated the phone helpline as excellent or good, compared to the website. The three highest used sources of information were person to person sources, with the fourth highest a helpline rather than an internet source.

Significantly, carers of people with dementia benefitted not just from encouragement but also from active support to find respite service information. This may relate to the significant burden that navigating service pathways adds to their role as carers [33]. Previous research has highlighted that carers and people with dementia value and benefit from guidance to make decisions around respite [33-36]. While carers in this study reported using GPs, practice nurses and family and friends for information support, the fact that high knowledge was associated with having used three or four sources of information suggests the need to improve access to both comprehensive respite information, as well as formal (system) support. The carers in this cohort were mostly elderly themselves. As such, limitations in physical mobility as well as their significant caring responsibilities would likely have reduced opportunities to physically interact with interpersonal sources for information including their peers, their local doctor or members of their extended family.

Overall, almost three quarters of carers in the study expressed an unmet need for respite. This result highlights the importance of respite for carers of people with dementia and the desire for respite as a primary outcome for themselves, not only as a secondary outcome of service use by the person they care for. This was particularly so for those carers supporting people with behavioural issues. Unmet need for respite has been highlighted in previous Australian and international studies [13, 37]. However, this study suggests that the new reforms in the Australian aged care sector may be inadequate in prioritising the unique need for respite services by people with dementia.

\section{Implications for policy and practice}

To better serve carers of people with dementia, this study highlights the need for promotional strategies using a wide variety of channels to provide respite service information. Greater promotion of new 'gateway' services, especially telephone helplines for respite information are also needed. Given the strong preference for interpersonal sources of information, the My Aged Care helpline could consider offering a named personal contact or 'case worker' whom carers of people with dementia can liaise with for follow up, rather than navigating their way through the Gateway system each time they call.

Offering a range of personal contact avenues (e.g. telephone, email, mail, and in-person) through multiorganisation directories may help to ensure simplified and accessible information about service pathways [38].

Table 4 Need factors associated with ever seeking information about respite

\begin{tabular}{|c|c|c|c|c|}
\hline Need factors & Total $n=83$ & Yes $n=71$ & No $n=12$ & $p^{*}$ \\
\hline Would you like more respite than you are currently receiving ${ }^{a}$, yes & 50 (68\%) & 46 (72\%) & $4(40 \%)$ & .068 \\
\hline $\begin{array}{l}\text { CG Zarit Burden Score }{ }^{\mathrm{a} b} \\
4 \text { items, } 5 \text { pt. scale, } 1 \text { (Never) to } 5 \text { (Nearly always) }\end{array}$ & $2.90(85 \%)$ & $2.96(87 \%)$ & $2.48(56 \%)$ & .075 \\
\hline $\begin{array}{l}\text { CG Role Captivity }{ }^{\mathrm{a}} \\
4 \text { items, } 4 \text { point scale } 1 \text { (Not at All) to } 4 \text { (Very Much) }\end{array}$ & $2.02(0.69)$ & $2.06(.72)$ & $1.78(.43)$ & .263 \\
\hline $\begin{array}{l}\text { CG, Self-efficacy }{ }^{a} \\
10 \text { items, } 10 \text { pt. Visual Analogue Scale }\end{array}$ & $6.67(1.82)$ & $6.69(1.79)$ & $7.02(2.06)$ & .301 \\
\hline $\begin{array}{l}\text { PWD, behavioural problems } \\
13 \text { items, } 4 \text { pt. scale, } 1 \text { (No days) to } 4 \text { ( } 5 \text { or more days) }\end{array}$ & $1.90(0.55)$ & $1.97(.56)$ & $1.48(.29)$ & .003 \\
\hline
\end{tabular}

Note. CG Caregiver, PWD Person with dementia. Continuous variables with Mann-Whitney U test unless otherwise labelled. ${ }^{*}$ Significance set at $p \leq .0125$ due to Bonferroni correction. ${ }^{\mathrm{a}}$ Valid percent is reported due to missing data. ${ }^{\mathrm{b}}$ Analysed via t-test 
Also, given the importance of positive social norms for respite use, promotional messages should be aimed at the general public and also include the initial and continuous training of care providers. Specifically respite information dissemination should target informal support networks, the primary care sector and carer support groups who should see it as central to their role to share knowledge and support potential uptake of respite services by carers [39]. Low use of the My Aged Care website suggests the need to improve website usability, and/or provide greater support and training to promote self-efficacy and digital literacy in the broader population.

Previous research suggests that promoting the benefits of respite for both the carer and the person with dementia is important $[12,40]$ as well as service access features such as the availability of transport services, extended operating hours, and variety of activities available. Promotional messages should portray an inclusive and accepting attitude towards respite use. Respite service information should highlight the flexibility of services and the benefits of earlier and more respite frequent use [12]. Positive messaging could assist with addressing other barriers to respite use including beliefs regarding poor service quality, carer guilt or the possibility of negative outcomes. In a comprehensive strategy, other barriers such as poor quality and/or lack of availability and flexibility in service provision must also be addressed [13, 14]. The absence of a significant relationship between 'wanting more respite' and current respite information seeking behaviour suggests the need to address service deficits. However, this could also be related to the stress and strain experienced by carers with a high need for respite, whereby the sheer effort of actions involved in help-seeking becomes an additional burden they cannot manage [16].

In this study the relationship between the person with dementia's behaviour with information seeking and higher unmet respite need highlights the significant physical and psychological strain on carers. Carers who reported receiving support to access services were less likely to report unmet needs. Dementia link workers have been found useful in supporting carers and people with dementia navigate and access services [41]. Psychoeducational interventions may also be useful to more effectively meet carer needs [42]. However, neither have been made available to Australian carers of people with dementia as part of new aged care reforms.

Finally, the results that carers who use more information sources have better knowledge of local services but more unmet need suggests that suitable respite services may not actually be available. In the context of new aged care reforms, this warrants further investigation and monitoring to determine whether reforms are delivering respite to those carers with the highest level of evaluated need.

\section{Limitations}

As there are no national or state-based lists of carers of people with dementia living in the community, survey distribution used multiple distribution channels to reach the target group, with an original mail out to any carer who had used emergency respite over the past year. This meant surveys would have been received by recipients who may not have been in the target group as they were not caring for someone with dementia, or were previously in the target group but changed status in the previous year if the person they had been giving care to had moved into residential care or passed away, or the caregiver had moved address or passed away. Previous research has also found low response rates for postal surveys to older populations [43]. The estimated response rate of $18 \%$ appears reasonable with these considerations. Whilst it is acknowledged that this was a small regional study so may not be representative of carers in other parts of Australia, it provides critical insights into how the needs of a particularly vulnerable group of help-seeking carers are navigating a service system in transition. In doing so, it provides timely insights to inform system and policy adjustment in a timely fashion.

As this study explores the experience of carers navigating a service system in transition it may not be reflective of longer term outcomes assuming that carer knowledge and access improves as the community and health services adjust to the changes. This is particularly true of the new Carer Gateway (which commenced in Australia in December 2016) and was not evaluated as an information source in this study. Note however, the Carer Gateway has no funding to support the delivery of planned respite services and will only play a role in referring information seekers with a need in this area back to he My Aged Care website. However, it would be worthwhile reassessing carers' knowledge, information seeking behaviours, and respite needs following the full implementation of the national aged care reforms.

\section{Conclusions}

These findings indicate the new reforms in the Australian aged care sector have not adequately responded to the needs of carers of people with dementia for respite information and support. Whilst most carers reported seeking respite information, few had used the new government gateway or found them useful and instead were relying on interpersonal information sources. Respite seeking was associated with caring for someone with behavioural problems and was reinforced by the provision of personal support. In response to the high need for respite services, there is an urgent need to test the efficacy of additional interventions to work alongside current national programs to promote positive respite knowledge, attitudes and uptake among carers and people with dementia. 
Community-wide interventions, such as social marketing programs, can promote the benefits of respite and availability of respite services but this study demonstrated that personal support is preferred to navigate the system and source relevant respite information. The current findings highlight the importance of professional and personal channels, including the primary care sector and carer support groups, in increasing awareness of, and improving access to, respite services.

\section{Abbreviations}

ACAT: Aged Care Assessment Team; CCRCs: Commonwealth Carer Respite Centres; CG: Care giver; GP: General practitioner; PWD: Person with dementia

\section{Acknowledgments}

The authors wish to thank the local support services, carer support groups, carers and people with dementia in the Illawarra and Shoalhaven regions who assisted with the distribution and completion of surveys.

\section{Funding}

- Alzheimer's Australia Dementia Research Foundation Grant

- NHMRC-ARC Dementia Research Development Fellowship APP 1107401

- Resthaven Incorporated Grant Fund

Note that the funding bodies had no involvement in the study design, the collection, analysis or interpretation of data, or the writing of this paper.

\section{Availability of data and materials}

The datasets used and/or analysed during the current study are not publically available due to the conditions of the Human Ethics approval.

\section{Authors' contributions}

LP was the lead investigator for the study and was primarily responsible for the study design and the drafting of the manuscript. $\mathrm{KJ}$ was primarily responsible for the analysis of the survey data and also played a role in writing and editing the manuscript. CN, EF, EP, DH and $\mathrm{HH}$ were all investigators on the project and contributed to the study design as well as to the editing and approval of the manuscript. All authors read and approved the final manuscript.

\section{Ethics approval and consent to participate}

The study protocol and materials were approved by the University of Wollongong Human Research Ethics Committee (HE15/027). All participants provided written consent.

\section{Consent for publication}

Not applicable.

\section{Competing interests}

The authors declare that they have no competing interests.

\section{Publisher's Note}

Springer Nature remains neutral with regard to jurisdictional claims in published maps and institutional affiliations.

\section{Author details}

${ }^{1}$ School of Health and Society, Faculty of Social Sciences, University of Wollongong, Wollongong, Australia. ${ }^{2}$ Australian Health Services Research Institute, University of Wollongong, Wollongong, Australia. ${ }^{3}$ School of Nursing and Midwifery, Faculty of Health, Engineering and Sciences, University of Southern Queensland, Toowoomba, Australia. ${ }^{4}$ Dementia Centre for Research Collaboration, Faculty of Health, Queensland University of Technology, Brisbane, Australia.
Received: 8 May 2018 Accepted: 10 December 2018

Published online: 07 January 2019

\section{References}

1. World Health Organization. Global action plan on the public health response to dementia 2017-2025. World Health Organization. 2017. http://apps.who.int/ iris/bitstream/handle/10665/259615/9789241513487-eng.pdfijsessionid= CEEEE5541A5C790F766151B3F5CEAE59? sequence=1 Accessed: 24 April 2018.

2. Australian Institute of Health and Welfare. Australia's health 2016. Australia's health series no. 15. Cat. no. AUS 199. 2016. https://www.aihw.gov.au/ getmedia/9844cefb-7745-4dd8-9ee2-f4d1c3d6a727/19787-AH16.pdf. aspx?inline=true Accessed: 24 April 2018.

3. National Collaborating Centre for Mental Health (UK). Dementia: a NICE-SCIE guideline on supporting people with dementia and their carers in health and social care. Leicester (UK): British psychological Society; 2007.

4. Alzheimer's Australia. The most difficult decision: dementia and the move into residential aged care. Alzheimer's Australia NSW. 2012. https://www. dementia.org.au/files/20121016-NSW-PUB-Moving_To_Res_Care.pdf Accessed: 1 May 2018

5. Banerjee S, Murray J, Foley B, Atkins L, Schneider J, Mann A. Predictors of institutionalisation in people with dementia. J Neurol Neurosurg Psychiatry. 2003;74(9):1315-6. https://doi.org/10.1136/jnnp.74.9.1315.

6. My Aged Care. Caring for someone. Australian Government. 2015. https:// www.myagedcare.gov.au/caring-someone Accessed: 30 January 2018.

7. Petty DM. Respite care: a flexible response to service fragmentation. In: Mace NL, editor. Dementia care: patient, family and community. Baltimore: MD: The Johns Hopkins Press; 1990. p. 243-69.

8. Howe A. Alzheimer's Australia respite review policy paper: paper 33. Prepared for the department of health and. Aging. 2013; https://www. dementia.org.au/files/NATIONAL/documents/Alzheimers-AustraliaNumbered-Publication-33.pdf.

9. Hamilton M, Giuntoli G, Johnson K, Fisher K. Transitioning Australian respite. Social policy research Centre. Australia: UNSW; 2016. https://www.sprc.unsw. edu.au/media/SPRCFile/Transitioning_Australian_Respite.pdf

10. Creswell A. Collateral damage: Australian carers' services caught between aged care and disability reforms. International journal of care and. Caring. 2017:1(2):275-9. https://doi.org/10.1332/239788217X14951899318122.

11. Brodaty H, Thomson C, Thompson C, Fine M. Why caregivers of people with dementia and memory loss don't use services. Int J Geriatr Psychiatry. 2005; 20(6):537-46. https://doi.org/10.1002/gps.1322.

12. Bruen W, Howe A. Respite care for people living with dementia. In: It's more than just a short break. Canberra: Alzheimer's Australia Paper 17; 2009. Available at: https://www.dementia.org.au/files/20090500_Nat_NP 17RespCarePplLivDem.pdf.

13. Phillipson L, Jones SC, Magee C. A review of the factors associated with the non-use of respite services by carers of people with dementia: implications for policy and practice. Health Soc Care Community. 2014;22(1):1-12. https://doi.org/10.1111/hsc.12036.

14. Neville C, Beattie E, Fielding E, MacAndrew M.. Literature review: use of respite by carers of people with dementia. Health Soc Care Community. 2015;23(1):51-63. https://doi.org/10.1111/hsc.12095.

15. Lord K, Livingston G, Cooper C. A systematic review of barriers and facilitators to and interventions for proxy decision-making by family carers of people with dementia. Int Psychogeriatr. 2015;27(8):1301-12. https://doi. org/10.1017/S1041610215000411.

16. Robinson A, Elder J, Emden C, Lea E, Turner P, Vickers J. Information pathways into dementia care services: family carers have their say. Dementia. 2009;8(1): 17-37. https:/doi.org/10.1177/1471301208099051.

17. Corbett A, Ballard C. Information provision services in dementia care. Int J Older People Nursing. 2011;6(3):217-26. https://doi.org/10.1111/j.17483743.2011.00289x

18. Stockwell-Smith G, Kellett U, Moyle W. Why carers of frail older people are not using available respite services: an Australian study. J Clin Nurs. 2010; 19(13-14):2057-64. https://doi.org/10.1111/j.1365-2702.2009.03139.x.

19. Werner P, Goldstein D, Karpas D, Chan L, Lai C. Help-seeking for dementia: a systematic review of the literature. Alzheimer Dis Assoc Disord. 2014;28(4): 299-310. https://doi.org/10.1097/WAD.0000000000000065.

20. Cotrell V, Engel R. The role of secondary supports in mediating formal services to dementia caregivers. J Gerontol Soc Work. 1998;30(3/4):117-32. https://doi.org/10.1300/J083v30n03_10. 
21. Hansen E, Robinson A, Mudge P, Crack G. Barriers to the provision of care for people with dementia and their carers in a rural community. Aust J Prim Health. 2005;11:72-9. https://doi.org/10.1071/PY05010.

22. Phillipson LJ, Jones SC, Magee CA. Factors associated with the use and nonuse of respite services by caregivers of people with dementia. Wollongong: University of Wollongong; 2012.

23. de Boer R, Yeend P. Aged Care (Living Longer Living Better) Bill 2013, Bills digest, 2012-13, vol. 106. Canberra: Australian Government; 2013.

24. Australian Government. About My Aged Care. 2013. https:/agedcare.health.gov.au/ programs-senvices/my-aged-care/about-my-aged-care Accessed: 24 March 2018.

25. Australian Government. Commonwealth Home Support Programme: Program manual 2017. Commonwealth of Australia (Department of Health). 2017. https://agedcare.health.gov.au/sites/g/files/net1426/f/documents/05_ 2017/chsp_manual_april_2017_final_0.pdf Accessed: 24 March 2018.

26. Australian Government. Carer Gateway launched to help carers. Department of Social Services, Australian Government; 2015. https:/www.dss.gov.au/disability-andcarers/feature/carer-gateway-launched-to-help-carers Accessed: 20 December 2015.

27. Department of Social Services. Commonwealth Respite and Carelink Centres. Australian Government. 2016. https://www.dss.gov.au/disabilityand-carers/programmes-services/for-carers/commonwealth-respite-andcarelink-centres Accessed: 24 March 2018.

28. Kodner DL. Consumer-directed services: lessons and implications for integrated systems of care. Int J Integr Care. 2003;3.

29. Douglass C, Visconti C. Factors influencing the use of adult day care by individuals with Alzheimer's disease: a multivariate examination of the California Alzheimer's disease diagnostic and treatment center program. Home Health Care Serv Q. 1998;17(2):53-69.

30. Pearlin L, Mullan J, Semple S, Skaff M. Caregiving and the stress process: an overview of concepts and their measures. Gerontologist. 1990;30(5):583-94.

31. Bedard M, Molloy D, Squire L, Dubois S, Lever J, O'Donnell M. The Zarit Burden Interview. Gerontologist. 2001;41(5):652-7.

32. Fortinsky RH, Kercher K, Burant CJ. Measurment and correlates of family caregiver self-efficacy for managing dementia. Aging Ment Health. 2002;6(2):153-60.

33. McPherson KMKN, Moloczij N, Cummins C. Improving the interface between informal carers and formal health and social services: a qualitative study. Int J Nurs Stud. 2014;51(3):418-29. https://doi.org/10.1016/j.jinurstu.2013.07.006.

34. King A, Parsons M. An evaluation of two respite models for older people and their informal caregivers. N Z Med J. 2005:118(1214):U1440.

35. Stirling C, Leggett S, Lloyd B, Scott J, Blizzard L, Quinn S, Robinson A. Decision aids for respite service choices by carers of people with dementia: development and pilot RCT. BMC Med Inform Decis Mak. 2012;12(21). https://doi.org/10.1186/1472-6947-12-21.

36. Low L-F, Yap M, Brodaty H. A systematic review of different models of home and community care services for older persons. BMC Health Serv Res. 2011;11(9). https://doi.org/10.1186/1472-6963-11-93.

37. Phillipson L, Magee C, Jones SC. Why carers of people with dementia do not utilise out-of-home respite services. Health Soc Care Community. 2013; 21(4):411-22. https://doi.org/10.1111/hsc.12030.

38. Chan J, Merriman B, Parmenter T, Stancliffe R. Rethinking respite policy for people with intellectual and developmental disabilities. J Policy Pract Intellect Disabil. 2012:9(2):120-6. https://doi.org/10.1111/j.1741-1130.2012.00332.x.

39. Arksey H, Jackson K, Croucher K, Weatherly H, Golder S, Hare P, et al. Review of respite services and short-term breaks for carers of people with dementia. National Health Service, Service Delivery Organisation. Heslington, York: Social Policy Research Unit. Available at: https:/www.york.ac.uk/inst/ spru/pubs/pdf/respiteEx.pdf

40. Vecchio N, Fitzgerald JA, Radford K, Fisher R. The association between cognitive impairment and community service use patterns in older people living in Australia. Health Soc Care Community. 2015;24(3):321-33. https:// doi.org/10.1111/hsc.12212.

41. Goeman D, Renehan E, Koch S. What is the effectiveness of the support worker role for people with dementia and their carers/family living in the community? http://sydney.edu.au/medicine/cdpc/documents/resources/keyworker-report.pdf Accessed: 2 May 2017.

42. Eagar K, Owen A, Williams K, Westera A, Marosszeky N, England R, Morris D. Effective caring: a synthesis of the international evidence on carer needs and interventions. In: Centre for Health Service Development. Wollongong: University of Wollongong: 2007. Available at: https:/ro.uow.edu.au/chsd/27/.

43. Palonen $\mathrm{M}$, Kaunonen $\mathrm{M}$, Åstedt-Kurki P. Exploring how to increase response rates to surveys of older people. Nurs Res. 2016;23(5):15-9. https://doi.org/10.7748/nr.23.5.15.

Ready to submit your research? Choose BMC and benefit from:

- fast, convenient online submission

- thorough peer review by experienced researchers in your field

- rapid publication on acceptance

- support for research data, including large and complex data types

- gold Open Access which fosters wider collaboration and increased citations

- maximum visibility for your research: over $100 \mathrm{M}$ website views per year

At $\mathrm{BMC}$, research is always in progress.

Learn more biomedcentral.com/submissions 